EMBRYARIDDLE
Aeronautical University

SCHOLARLY COMMONS
International Journal of Aviation, Aeronautics, and Aerospace

2-19-2016

\title{
Analysis of the Federal Aviation Administration's Small UAS Regulations for Hobbyist and Recreational Users
}

\author{
Jon Loffi \\ Oklahoma State University - Main Campus, jon.loffi@okstate.edu \\ Ryan J. Wallace \\ Polk State College, ryan.wallace@erau.edu \\ Christopher S. Ison \\ The Ison Law Group, christopher@thepilotlawyer.com
}

Follow this and additional works at: https://commons.erau.edu/ijaaa

Part of the Other Legal Studies Commons

\section{Scholarly Commons Citation}

Loffi, J., Wallace, R. J., \& Ison, C. S. (2016). Analysis of the Federal Aviation Administration's Small UAS Regulations for Hobbyist and Recreational Users. International Journal of Aviation, Aeronautics, and Aerospace, 3(1). https://doi.org/10.15394/ijaaa.2016.1111

This Article is brought to you for free and open access by the Journals at Scholarly Commons. It has been accepted for inclusion in International Journal of Aviation, Aeronautics, and Aerospace by an authorized administrator of Scholarly Commons. For more information, please contact commons@erau.edu. 
In recent years, the Federal Aviation Administration has encountered a complex conundrum related to UAS integration. Under charge from Congress to seamlessly integrate UAS platforms into the existing National Airspace System (NAS), the agency is simultaneously responsible to ensuring the intermingling of unmanned and manned aircraft operations can be performed in a safe manner. Statute 49 U.S.C. $§ 40103$ charges the FAA to "regulate aircraft operations conducted in the NAS, which include UAS operations, to protect persons and property on the ground, and to prevent collisions between aircraft and other aircraft or objects" (FAA, n.d.b, p. 1).

\section{Problem}

The proliferation of small UAS platforms for hobby and recreational use has created new safety challenges for the agency. Congressional Subcommittee on Aviation Chairman Frank LoBiondo echoed these concerns in his opening statement during a U.S. House of Representatives Transportation \& Infrastructure Subcommittee (2015) meeting which addressed "Ensuring Aviation Safety in the Era of Unmanned Aircraft Systems":

- Unmanned aircraft systems, or UAS, represent the latest frontier in aviation technology. While still a new industry, UAS are already contributing to our economy and changing how companies do business... But like any other new technology, UAS bring new challenges as well. In the past year, pilots have been reporting sightings of UAS near airports at an accelerating rate. In 2014, the FAA received 238 reports of drone sightings. In 2015, the number has already exceeded 600.

- Safety is paramount in aviation and the increased number of suspected sightings raises serious questions. Some of these reports involved airliners and occurred at low altitudes near the nation's busiest airports. Other reports involve pilots of general aviation aircraft in less busy airspace. The real possibility of a mid-air collision must be taken seriously to prevent tragic consequences.

- To be clear, it is also my understanding that some of these reported sightings may involve something other than a consumer unwisely operating their new gadget in busy controlled airspace or restricted airspace. In at least some cases, the reported UAS may have been a government-operated aircraft or a lawfully operated UAS or simply a bird in flight. 
- To that end, we need to understand what precisely is going on in our airspace - what's the actual risk and how do we manage and mitigate it? With retailers readying for significant UAS purchases by American consumers this upcoming [2015] holiday season, this conversation and subsequent action cannot wait. There are real consequences if we are not cautious enough, though we must not go to extreme which could unnecessarily restrict UAS industry's growth and innovation here in the United States because of so-called false positives. (p. 1)

\section{Purpose}

The study sought to better understand the implications and impact of recent FAA regulatory and policy initiatives regarding sUAS systems operated for hobby or recreational purposes.

\section{Method}

The framework used to inform this study is a hybrid qualitative design blending case study, document analysis, and conceptual analysis modes of inquiry. This study examined incidents of alleged misuse of unmanned aerial systems and regulatory efforts by the Federal Aviation Administration to regulate the introduction of UAS into the national airspace system.

The study sought to answer the following research questions:

1. What regulatory measures currently exist to deter unsafe use of sUAS platforms by recreational or hobby operators?

2. What mechanisms are currently in place to hold sUAS recreational or hobby operators responsible for unsafe operations?

The study evaluated 40 official documents and reports from the FAA, industry members, academic sources, and news agencies to identify key concepts cogent to the presented research questions. The study attempted to provide an explanation of the various concepts in detail, based on the available conceptual and documentary data, as well as identify and highlight potential vulnerabilities where a lack of data did not warrant specific conclusions. 


\section{Problem Significance}

\section{Impact to the National Airspace System}

A study of UAS sightings and encounters by Gettinger and Michel (2015) revealed the problem of near mid-air collisions between UAS platforms and aircraft is far worse than previously thought. Using a combination of internal reporting data released by the FAA and pilot and controller reports submitted to the NASA Aviation Safety Reporting System (ASRS), the researchers identified more than 921 UAS sightings or near encounters with aircraft in the 21-month period from February 2014-October 2015 (Gettinger \& Michel, 2015). Of those incidents, 321 were categorized as close encounters, in which a pilot reported a near mid-air collision, indicated a UAS presented a proximity hazard, took evasive action, or the manned aircraft and UAS closed to within 500 feet (Gettinger \& Michel, 2015). Perhaps more alarming, is that in $20 \%$ of the cases, pilots reported coming within less than 50 feet of a UAS. Nearly 1 in 12 pilots reported maneuvering or taking evasive action to avoid a UAS collision (Gettinger \& Michel, 2015).

\section{Impact to Persons \& Property}

UAS platforms have an equally poor record of impacting people and property on the ground. On July 17, 2015, a UAS operator conducting a flight in the vicinity of wildfires near San Bernardino, California interrupted aerial firefighting operations. Flying at 12,000 feet, the small 3-foot by 4-foot UAS craft came within proximity of two aerial firefighting tankers, forcing one to jettison its 2,000 gallon payload of fire retardant (Steinberg \& Nelson, 2015). Three aerial firefighting aircraft were grounded as a result of the UAS encounter (Steinberg \& Nelson, 2015). Aircraft were evacuated from the area for 20 minutes, contributing to the growth of the wildfire (Registration and Marking Requirements for Small Unmanned Aircraft Interim Final Rule [80 FR 78593], 2015). Fire personnel estimated that had the UAS craft not interfered, the fire could have been contained to within 100 acres (80 FR 78593, 2015).

On September 4, 2015, a UAS operator lost control of his UAS, crashing it into an unoccupied section of seating in New York City's Armstrong Stadium during the US Open Tournament (Goff, 2015). On September 5, 2015, a UAS operator allegedly lost connection with his DJI Inspire 1, while maneuvering it out of the path of four parachutists. The UAS reportedly came within 25 feet of the descending jumpers and crashed shortly thereafter into the glass wall of an occupied University of Kentucky Commonwealth Stadium patio (McKay, 2016). On September 12, 2015, an operator lost control of his UAS platform near an 
outdoor movie theater in Pasadena, California. Wreckage from the UAS craft caused head injuries to an 11-month old girl (80 FR 78593, 2015). On October 26, 2015, a UAS impacted electrical conductors in West Hollywood, California, causing detachment of a section of electrical line and disrupting utility service to 640 customers (80 FR 78593, 2015).

\section{FAA Strategy: UAS Safety through Accountability}

\section{UAS Registration}

Registration requirements. On December 21, 2015, the FAA unveiled its online registration system for sUAS craft weighing between $0.55 \mathrm{lbs}$ and $55 \mathrm{lbs}$ (FAA, 2016b). UAS operators who acquired and flew their UAS prior to December 21 were given until February 19, 2016 to complete the registration process (FAA, 2016b). Those who acquired UAS platforms after December 21, 2015 were required to register prior to their first outdoor operation (FAA, 2016b). To entice operators to register, the FAA waived the $\$ 5$ registration fee for the first 30 days after releasing the registration system (FAA, 2016b).

The system had several distinct limitations, foremost, that the online registration process was limited to supporting 14 CFR Part 48 registrations for sUAS platforms operated by hobbyists and modelers (FAA, 2016b; FAA, n.d.b). UAS craft operated for other than hobby or recreational use, or those larger than the $55 \mathrm{lb}$ weight threshold, were required to be registered via a paper-based system (FAA, 2016b).

A January 21, 2016 public inquiry to the UAS registration helpline revealed more than 325,930 individual accounts had been created in the UAS database. It is unknown how many individual UAS craft are registered, as individuals may register several UAS platforms under one account (80 FR 78593, 2015). It is difficult to speculate about the total population of sUAS platforms in the U.S., but the FAA estimated sUAS sales would top 1.6 million in 2015 alone (Morris \& Thurston, 2015). Sales are projected to balloon to 1.9 million in 2016 and continue to grow by nearly $23 \%$ annually, reaching nearly 11 million sUAS craft by 2020 (Morris \& Thurston, 2015).

Purpose of UAS registration. Perhaps the most significant hurdle for the FAA is ensuring UAS operator compliance with operational and safety rules. Identifying non-compliant UAS operators, however, presents a unique challenge for the agency. Because UAS operators can control a craft remotely at distance, 
operator identification is problematic for both FAA and law enforcement personnel. Morris and Thurston (2015) stated:

Taking enforcement action requires identifying an individual or entity responsible for the operation. That is often difficult due to the nature of sUAS operations. An operator can fly an unmanned aircraft from miles away, generally with no way to trace the aircraft back to its operator. Locating violators is also a challenge, as very few of these aircraft are registered in any federal database and rarely will they have identifiable markings such as those used for conventional manned aircraft. (p. 42)

Without accompanying markings to tie the identity of a UAS operator to a specific UAS craft, violators are able to maintain anonymity. The relatively low cost of sUAS craft make them an essentially disposable product, which is likely to be readily abandoned if an operator commits a known violation and fears criminal prosecution, FAA administrative punishment, civil fines, or personal liability. Because UAS platforms allow operators to maintain relatively long standoff distances from the device, law enforcement personnel may be unable to locate the operator in proximity of an incident or accident scene. Moreover, the relatively small footprint of sUAS operator control equipment — often just a handheld remote control device or small laptop-sized control station-further aids an operator in evading detection. Several anecdotes of recent sUAS incidents or accidents exemplify this phenomenon:

On June 29, 2015, a UAS operator crashed a small, two-pound UAS into a building along the route of the Seattle Pride Parade in Washington. After impacting the structure, the UAS lost control and struck a woman on the ground, knocking her unconscious ("Drone," 2015). Law enforcement personnel were initially unable to locate the pilot at the scene ("Drone," 2015).

On November 11, 2015, a UAS operator reportedly crashed a small, DJI Phantom III into the Seattle Ferris Wheel. The UAS caused no apparent harm to the ride, however, it did damage to a nearby plastic table (Ungureanu, 2015). Law enforcement personnel were unable to locate the pilot (Ungureanu, 2015).

The primary purpose of the UAS registration requirement is to promote safety through operator accountability. The FAA clearly identifies this purpose in the Interim Final Rule of Registration and Marking Requirements for Small Unmanned Aircraft (2015): 
Registration will provide a means to quickly identify these small unmanned aircraft in the event of an incident or accident involving the sUAS. . . A Aircraft registration is necessary to ensure personal accountability among all users of the NAS. . . A Aircraft registration also allows the FAA and law enforcement agencies to address non-compliance by providing a means by which to identify an aircraft's owner and operator. . . As more small unmanned aircraft enter the NAS, the risk of unsafe operations will increase without a means by which to identify these small unmanned aircraft in the event of an incident or accident. (80 FR 78593, 2015, p. 1)

The Interim Final Rule cites several methods to address violations of the mandatory registration policy. Failure to register a UAS has the potential to carry stiff FAA penalties. Operators who fail to register their UAS can incur civil penalties up to $\$ 27,500$, criminal fines up to $\$ 250,000$, or even jail time of up to three years (80 FR 78593, 2015). Alternatively, the FAA can elect to correct infractions via remedial education or administrative action, taking the form of a warning letter or letter of correction (FAA, n.d.c).

Currently, the FAA has tempered its UAS enforcement policy in favor of providing corrective education to UAS operators. According to FAA Policy \& Plans Economic Analysis Division Analysts Morris \& Thurston (2015):

Many of the owners of these new sUAS may have no prior aviation experience and have little or no understanding of the NAS, let alone knowledge of the safe operating requirements. Aircraft registration provides an immediate and direct opportunity for the agency to engage and educate these new users prior to operating their unmanned aircraft, thus helping to mitigate the risk associated with the influx of operations. (p. 9)

The Interim Final Rule of Registration and Marking Requirements for Small Unmanned Aircraft (2015) echoes these sentiments:

Registration of small unmanned aircraft also provides an immediate and direct opportunity for the agency to educate sUAS owners on safety requirements before they begin operating...With the current unprecedented proliferation of new sUAS, registration allows the FAA a direct and immediate opportunity to educate sUAS owners. (p. 1) 
While the FAA touts the benefits of educating sUAS operators via the registration system, the agency makes it clear that teaching safe sUAS operating practices is secondary to ensuring operator accountability: "While registration allows the agency an opportunity to educate sUAS operators, the primary purpose of registration is to identify the aircraft owner" (80 FR 78593, 2015, p. 1).

\section{Ensuring Compliance: Education}

The FAA's strategy to educate rather than punish UAS operators for infractions is further supported by the agency's internal policy shift away from pursuing enforcement action against operators who posted video evidence of possible violations to popular video site YouTube.

The FAA backtracked from its original policy in April 2015, when FAA Flight Standards Service Director John Duncan informed agency inspectors that "a video is ordinarily not sufficient evidence alone to determine that a drone violated federal rules" (Bachman, 2015, p. 1). In lieu of warning letters or formal enforcement actions, the agency has elected to send educational letters to UAS operators, describing the regulatory restrictions that apply to UAS operations (Bachman, 2015).

"No Drone Zone" campaign. In 2015, the FAA established the "No Drone Zone" initiative, designed to educate the public about prohibited drone operating areas (Kauh, 2015). The initiative was designed to curb UAS incidents at major sporting events, such as the Super Bowl and around Washington D.C. (Kauh, 2015). The agency also created a digital toolkit containing several iterations of warning signage, which feature a quad-copter style UAS in the background of a red prohibition sign (FAA, 2015d). These preemptive efforts to stave off UAS operations appear to show the agency's awareness that many operators are unfamiliar with the geographical restrictions associated with safe UAS operations.

"Know Before You Fly" campaign. The FAA has stepped up efforts in recent months to educate UAS operators who intend to use their platforms for hobby and recreational use. Dubbed the "Know Before You Fly" campaign, the agency has secured partnerships with industry associations, including the Association for Unmanned Vehicle Systems International (AUVSI) and Academy of Model Aeronautics (AMA) to promote safe, responsible use of UAS platforms (FAA, 2015c; AUVSI \& AMA, 2015). The campaign includes promotional educational material for recreational and hobbyist UAS operators and includes safety guidelines, a summary of regulatory restrictions, and UAS registration assistance. 
In support of the education initiative, the FAA has also released a free $\mathrm{iOS}$ smartphone app, B4UFLY; a similar app has been released for beta testing for Android users (FAA, 2016a). The app aids UAS operators in determining location and operational restrictions for flying their UAS (FAA, 2016a). The app provides real-time information on UAS restrictions based on both temporary conditions such as Temporary Flight Restrictions as well as permanent laws and regulations including PL-112-95, the Federal Aviation Regulations, and National Park Service rules (FAA, n.d.a).

While the app is a useful decision-making tool, it comes with several caveats that clearly articulate that operational safety responsibility is squarely in the hands of the operator. According to B4UFLY Q\&A Guide (2015):

Users should be aware that regardless of the B4UFLY's status indicator, the FAA has the authority to use enforcement action against anyone who flies an unmanned aircraft, including model aircraft, carelessly or recklessly in a way that endangers the safety of the National Airspace System or people or property on the ground. (p. 3)

Perhaps more importantly, the B4UFLY Q\&A Guide (FAA, n.d.a) evades directly answering the posed question: "If I send flight information to the FAA using B4UFLY, can it be used against me in an enforcement case?" (p. 3). In response, the B4UFLY Q\&A Guide reiterates the FAA's authority to engage in pursuing enforcement against anyone endangering either the airspace system or individuals (FAA, n.d.a).

FAA policies shifting. There is evidence to suggest that the FAA's benign, educational approach to UAS enforcement is starting to shift. In October 2015, the FAA signed an agreement with CACI International to test passive detection system technology to locate operators of UAS craft operating in the vicinity of airports ("FAA," 2015). Such a move seems to indicate a possible policy shift to more proactively engage unauthorized UAS operations.

October 2015 also marked a significant deviation from the FAA's traditionally soft handed approach to drone enforcement, when the agency handed down an unprecedented $\$ 1.9$ million civil penalty against Chicago-based UAS operator SkyPan International. The agency cited 65 unauthorized "careless or reckless operations" involving several UAS flights within "highly-restricted New York Class B airspace" conducted between March 2012 and December 2014 as the impetus for the fine (Grady, 2015, p. 1). 


\section{Ensuring Compliance: Civil Enforcement}

The FAA has several civil enforcement tools to punish sUAS violations. The FAA may elect to take no action, pursue an administrative action, or pursue a legal enforcement action. Administrative action may take the form of a warning notice or letter of correction. A warning notice is similar to a traffic warning, in that the FAA retains a record of the event, but declines to pursue further punitive action. A letter of correction outlines required action for the recipient, which if complied with, results in no further action by the FAA. Failure to comply with a letter of correction would elevate the incident to a legal enforcement action. Legal enforcement actions can include either certificate action [applies only to FAAcertificated individuals] or civil penalties. In the case of certificated aviators, the FAA may take action against that airmen's certificate, including suspension or revocation. Alternatively, the FAA may elect to pursue legal enforcement action by levying a civil penalty, or fine. In certain instances, the FAA may also refer cases to the Department of Justice for criminal prosecution.

History of UAS enforcement actions. On October 17, 2011, Mr. Raphael Pirker [Swiss Citizen] was commissioned to fly his unmanned powered aircraft for the University of Virginia. He provided photographs and videos of the Virginia Medical Center campus to an advertising agency (Ahlers, 2014). The aircraft flown by Pirker was a remotely operated Ritewing Zephyr foam constructed fixed-wing aircraft considered to be in the "model" category (Harrison, 2014).

The FAA accused Pirker of flying his aircraft in near proximity to individuals, near pedestrians on a crowded street, structures, a University of Virginia tunnel, and within 100 feet of an active heliport. They further claimed the aircraft was operated in an unsafe manner that endangered the National Airspace and persons or property on the ground (Huerta v. Pirker, 2014; Ahlers, 2014).

The FAA proposed a $\$ 10,000$ civil penalty would be levied against Pirker based on a violation of 14 C.F.R. $\S$ 91.13(a), which alleges careless or reckless operation of an unmanned aircraft (Huerta v. Pirker, 2014). Pirker appealed the FAA decision to an administrative law judge with the National Transportation Safety Board (NTSB). The administrative judge, Patrick Geraghty, vacated the FAA Administrator's order of assessment against Pirker. Acording to Carey (2014) Judge Geraghty stated, "The FAA has no regulations that apply to model aircraft or that classify model aircraft as an unmanned aircraft system" (para. 1). 
The FAA appealed the NTSB decision saying they applied the rules of construction, which allow the administrator of the FAA to interpret statutes and regulations in accordance with his responsibilities to regulate the operation of aircraft. The FAA cited Tile 49 U.S.C. § 40102(a)(6), which "defines aircraft as any contrivance invented, used, or designed to navigate, or fly in, the air" (Huerta v. Pirker, 2014, p. 5).

At issue in the Huerta v. Pirker case is what defines an aircraft for regulation by the FAA. Pirker's attorneys claimed at the time of Pirker's flight no regulations or rules that apply for enforcement purposes on the part of the FAA existed for model aircraft flights. They further claimed, "The FAA's unprecedented regulation-by-policy of a previously unregulated device so as to impose an unprecedented (and unenforceable) ban on 'business' use of that technology" (Huerta v. Pirker, 2014, p. 3). Additionally, the FAA's Advisory Circular AC 9157 , issued in 1981, requested only voluntary compliance with safety standards for model aircraft operators and in this advisory circular no distinction existed to classify a model operator from a commercial operator (Huerta v. Pirker, 2014).

The FAA was successful in its appeal to the NTSB's full five-member Board and in the final decision by the NTSB the FAA now has the authority to fine operators of unmanned aerial systems for careless or reckless flying (Kesselman, 2014).

The first notice the FAA published regarding the prohibition of the operations of unmanned aircraft systems for commercial purposes came in 2007 with a Notice of Policy in the Federal Register. The notice of policy was titled Unmanned Aircraft Operations in the National Airspace System. In this notice a new class of aerial device was referred to as unmanned aircraft systems, which included the class "remotely controlled model aircraft of any size and weight" ("FAA Unmanned," 2007).

This case exemplifies the challenges faced by the FAA in regulating a burgeoning technology that seems to be expanding exponentially. One could infer by the publicity generated by the Pirker case the FAA is now making an attempt to educate and inform UAS operators, whether hobbyists or commercial operators. The release of the FAA app "B4UFLY" is one example of this new approach and in the opinion of the authors may be a "softening" of the FAA's approach to enforce regulations regarding UAS before assessing fines.

Current FAA Civil Enforcement policies. The application of civil enforcement is guided by FAA Order 8000.373, the Federal Aviation 
Administration Compliance Philosophy. This national policy establishes a set of philosophical principles by which the FAA maintains "strategic safety oversight" of the National Airspace System (FAA, 2015b, p. 1). The FAA Compliance Philosophy (FAA, 2015b) identifies the following key principles:

- The FAA's role is to establish regulatory standards to ensure safe operations in the National Airspace System

- The safety system is reliant on the voluntary compliance

- Aviation users have a legal obligation to comply with regulatory standards

- The FAA's goal is to use the "most effective means to return an individual or entity...to full compliance and prevent reoccurrence" (p. 1)

- The FAA acknowledges some deviations are unintentional, and should be corrected through training, education, or process improvement, with the intent of preventing repeat occurrences

- The FAA views intentional or reckless deviations as presenting an "unacceptable risk to safety...posing the highest risk to safe operation of the NAS, and thus requiring strong enforcement" ( $p$. 2).

- The FAA cites the need for remedial enforcement or retraining to address deficiencies of competence or qualification

- The FAA states that criminal activities will be addressed via enforcement or other legal enforcement measures

Enforcement of UAS operator infractions is likely to remain case-specific, as it is for certificated aviators. According to AC 00-46E, the FAA considers 10 key factors when determining enforcement options:

- Nature of the violation

- Whether the violation was inadvertent or deliberate

- The certificate holder's level of experience \& responsibility

- Attitude of the violator

- The hazard to the safety of others which should have been foreseen

- Action taken by the employer or other government authority

- Length of time which has elapsed since violation

- The certificate holder's use of the certificate

- The need for special deterrent action in a particular regulatory area or segment of the aviation community 
- Presence of any factors involving national interest, such as the use of aircraft for criminal purposes (p. 3-4)

Realizing the potential for UAS infractions, the FAA has published specific guidance to aid in determining appropriate legal enforcement. According to FAA Order 2150.3B CHG 6, Compliance and Enforcement Bulletin 2014-2 and subsequent FAA Order 2150.3B, Appendix H:

Administrative or enforcement action:

- A first-time, inadvertent violation that poses a low actual or potential risk to safety, but one in which the aviation safety inspector determines compliance cannot be gained through education warrants administrative action (warning notices or letters of correction, with associated documentation)

- When sufficient evidence exists to support a violation that poses a medium or high actual or potential risk to safety, legal enforcement action is appropriate (FAA, 2015a, p. H-9, H-10)

Civil Penalties are applied in accordance with Order 2150.3B, Chapter 7 and Appendix B:

- A violation that poses a medium actual or potential risk to safety generally warrants a civil penalty in the minimum to moderate range.

- A violation that poses a high actual or potential risk to safety generally warrants a civil penalty in the maximum range.

- Repeated or intentional violations [emphasis added] generally warrant a civil penalty in the applicable maximum range. (FAA, 2015a, p. H-10)

A common question circulating among certificated aviators revolves around whether an individual's FAA-issued aeronautical certificates are at risk when performing hobby or recreational UAS activities. An analysis of FAA enforcement guidance indicates the agency has already paved the way to initiate enforcement actions against certificated aviators for UAS violations, even if a certificate is not required for the particular UAS operation.

For deliberate, egregious violation by a certificate holder, regardless of whether the certificate holder is exercising the privileges of the certificate in connection with the violations associated with a UAS operation, 
certificate action may be appropriate. Such certificate action may be in addition to a civil penalty [emphasis added]. (FAA, 2015a, p. H-10)

In fact, possession of an aeronautical certificate is likely to heighten punitive action by the FAA. FAAO 2150.3B, Appendix H further states:

A certificate holder should appreciate the potential for endangerment that operating a UAS contrary to the FAA's safety regulations may cause. Accordingly, a violator's status as a certificate holder is an aggravating factor [emphasis added] that may warrant a civil penalty above the moderate range for a single, first-time, inadvertent violation [emphasis added]. (FAA, 2015a, p. H-10, Note 5).

Aviation Safety \& Reporting System (ASRS) applicability. Perhaps one of the most interesting FAA enforcement questions relate to the applicability of the ASRS program to non-certificated UAS operators.

The ASRS program is a voluntary reporting system to encourage "the identification and reporting of deficiencies and discrepancies in the [National Airspace] system" (FAA, 2011, p. 1). While primarily intended for certificated aviation professionals such as pilots, air traffic controllers, maintenance personnel, and other individuals holding FAA-granted licenses, the program does not exclude non-certificated holders from using the system. AC-00-46E states:

The cooperative safety reporting program invites pilots, controllers, Flight Attendants (F/A), maintenance personnel, dispatchers and other users of the National Airspace System (NAS), or any other person, to report to NASA actual or potential discrepancies or deficiencies involving the safety of aviation operations [emphasis added]. (p. 1)

This broad-based inclusionary text implies that the ASRS program is open to non-certificated UAS operators, such as those flying UAS platforms for hobby or recreational purposes. Most important is the FAA's stance regarding ASRS reporting. AC-00-46E states:

The FAA considers the filing of a [ASRS] report with NASA concerning an incident or occurrence involving a violation of 49 U.S.C. Subtitle VII or the 14 CFR to be indicative of a constructive attitude. Such an attitude will tend to prevent future violations. Accordingly, although a finding of violation may be made, neither a civil penalty nor certificate suspension will be imposed if [emphasis added]: 
- The violation was inadvertent and not deliberate;

- The violation did not involve a criminal offense, accident, or action under 49 U.S.C. $\$ 44709$, which discloses a lack of qualification or competency, which is wholly excluded from this policy;

- The person has not been found in any prior FAA enforcement action to have committed a violation of 49 U.S.C. Subtitle VII of any regulation promulgated there for a period of 5 years prior to the date of occurrence; and

- The person proves that, within 10 days after the violation, or date when the person became aware or should have been aware of the violation, he or she completed and delivered or mailed a written report of the incident or occurrence to NASA. (p. 4)

Most notably, the ASRS system is already being employed by some UAS operators. In a 50-event sampling of reports involving UAS platforms, ASRS (2015) reported 11 such events were self-reported by UAS operators. While 10 of the events involved government or military UAS activities, one notable incident (ACN1077518) was filed by a certificated UAS operator reportedly flying the platform for personal use (ASRS, 2015). The precedent of self-reporting by UAS operators, coupled with the lack of exclusionary language for non-certificated operators implies that the FAA would be compelled to apply similar enforcement protections to non-certificated self-reporters that is currently offered to certificated self-reporters.

\section{Ensuring Compliance: Criminal Enforcement}

While UAS operators may not necessarily be pursued for enforcement action by the FAA in the short term, they are still subject to possible criminal prosecution from local, state, or federal law enforcement personnel for infractions resulting from the improper use of UAS platforms.

There are a multitude of criminal statutes and charges that could be applied to the recreational operation of a UAS, depending upon the circumstances and intent of the UAS operator. For example, a UAS operator may be charged with Aggravated Assault if s/he intends to use the UAS in such a manner so as to create an intentional, unlawful threat to do violence to the person of another, coupled with the apparent ability to do so, and doing some act with the UAS to create a wellfounded fear in the mind of the other person that such violence is imminent. Taking that concept a little further, if a UAS operator were to make good on his threat of assault and actually and intentionally touch or strike another person with the UAS, 
against the will of the other person, or intentionally cause bodily harm to another person with the UAS, then s/he could be criminally liable for Aggravated Battery. In both scenarios, the use of the UAS can be said to be a deadly weapon - an object that is inherently deadly or dangerous, or used in such a manner so as to likely cause death or great bodily harm.

Certain state statutes for trespass could also trip-up recreational drone users. In general, trespass is the act of entering and remaining upon the premises of another without permission, invitation, or lawful authority. Some states have defined the "entering" of real property to mean going upon or over real property, either in person or by causing an object to go upon or over real property. In those jurisdictions, recreational UAS operators should make sure they have the permission of the land owner prior to flying over the property.

Operators of UASs should also be aware that, depending upon their actions and intent, they could be charged with criminal Video Voyeurism. In Florida, for example, a person who records for his own amusement, entertainment, sexual arousal, gratification, or profit, or for the purpose of degrading or abusing another person, without that person's knowledge and consent, who is dressing, undressing, or privately exposing the body, at a place and time when that person has a reasonable expectation of privacy, could be found guilty of video voyeurism. Such laws vary from state to state.

Additionally, some states may have the crime of Reckless Endangerment, which could be applied to the operation of a UAS under certain circumstances. Under a reckless endangerment scenario, the UAS operator could be charged if s/he operates the UAS in such a manner so as to put him- or herself or third parties at risk of injury, or has actually caused injury to third parties. This differs from an Aggravated Battery charge because under a Reckless Endangerment scenario, the UAS operator does not have the intent to injure or harm other people but does so due to his or her reckless operation of the UAS.

An analysis of 765 UAS encounter reports released from the FAA, revealed that more than $66 \%$ of the cases were referred to local, state, or federal law enforcement personnel for investigation or other action (FAA, 2015e).

Criminal enforcement appears by far to be the most predominant form of punitive action against improper or unsafe operation of UAS platforms. The reviewed documents provided several examples of prosecutorial enforcement of UAS activities: 
- San Bernadino, California County District Attorney Mike Ramos indicated UAS operators would be prosecuted for murder if the "intentional act of a drone" caused injury or death to aerial or ground wild firefighting personnel ("D.A.," 2015, p. 1). County authorities offered $\$ 75,000$ in rewards to for information leading to the prosecution of UAS operators who interfered with 2015 summer firefighting operations (Hamilton \& Rocha, 2015).

- In September 2015, the Los Angeles City Attorney charged a UAS operator with obstructing police after his UAS platform came within close proximity of a police helicopter (Serna, 2015).

- In October 2015, Seattle authorities located the operator that knocked out a woman at a Seattle Gay Pride Parade. The operator was charged with reckless endangerment (Miletich, 2015).

- The operator of a UAS platform alleged to have crashed into an unoccupied section of the New York City Armstrong Stadium during the U.S. Open tournament was charged with reckless endangerment (Goff, 2015).

- The operator who lost control of his UAS platform near the University of Kentucky Stadium was charged with wanton endangerment and criminal trespassing (McKay, 2016).

- Some communities have even passed new laws or ordinances to cope with rising UAS incidents.

- The Los Angeles City Council passed a unanimous ordinance in 2015 in which a UAS operator could face up to $\$ 1,000$ in fines and incarcerated for up to six months for flying greater than 500 feet, within a five mile proximity of an airport, or within 25 feet of a person (Tse, 2015).

\section{Ensuring Compliance: Civil Liability}

While not directly tied to traditional FAA enforcement actions, civil liability resulting from improper or reckless use of UAS platforms is likely to play a significant role in enforcing safe operation and regulatory compliance.

UAS operators must be acutely aware of the potential liability implications of improper UAS operation. While it is likely property damage or injury resulting from recreational UAS operation will be covered by existing homeowners policies, such coverage may be limited or even excluded, based on the individual policyspecific provisions and language (Schrimpf \& Russ, 2015). According to Schrimpf and Klingaman (2015), it is important to note how each policy defines "aircraft," as many policies specifically exclude liability for injuries or damages resulting from "ownership, maintenance, operation, use, loading, or unloading" (p. 1). Moreover, the purpose of the operation may also exclude coverage. Use of a UAS for business purposes, for example, may invalidate a homeowner's coverage (Schrimpf \& Russ, 2015). Additionally, the intent of the operator may be called into question. 
Violation of a policy's intentional act exclusion may result in an insured forfeiting coverage, if the operation was determined to be deliberate rather than reckless (Schrimpf \& Russ, 2015).

In lieu of relying on homeowners insurance to provide liability protections, membership in the Academy of Model Aeronautics provides up to \$2,500,000 of liability coverage for bodily injury and property damage incurred from UAS operations that occur within the confines of the AMA National Safety Codes (AMA, 2014). This coverage has specific limitations and expressly excludes injury to household family members, UAS operations used for business purposes (AMA, 2014). Despite these restrictions, the coverage does include theft, fire, and vandalism protection (AMA, 2014).

It is foreseeable that insurers will attempt to tie known violations of FAA regulatory policy for UAS operation with intentional act policy exclusions. Moreover, as UAS injury and property damage claims become more commonplace, it is highly probable that most homeowner insurers will exempt UAS operations from coverage. According to Abrams (2015), "some companies are starting to include exclusions that encompass recreational drones in anticipation of the increase in rookie fliers" (p. 1). These insurance provisions would leave unsafe and reckless UAS operators directly liable for damage and injury resulting from their UAS flying activities.

In the event of a UAS accident that causes injury or property damage, it is also probable that the UAS platform may be irreparably damaged. Alternatively, the UAS owner may elect to not attempt retrieval of the platform in an attempt to preserve anonymity and avoid possible legal ramifications or tort liability. While UAS platform cost is highly variable, the most capable and hazardous platforms generally exceed $\$ 1,000$. It is highly unlikely that most insurance policies would cover replacement or repair of a UAS platform for damage resulting from improper operation of the device. High replacement costs may deter some operators who damage or destroy their UAS craft from replacing their devices. The FAA estimates that only $80 \%$ of operators will replace their UAS platform if it is destroyed (Morris \& Thurston, 2015). Succinctly, it is likely that the economics of unsafe operations, may play a role in correcting unsafe or reckless UAS activities.

\section{Conclusions}

While UAS integration is still very much in its infantile stages, several regulatory mechanisms exist to deter unsafe UAS operations. Foremost, is the FAA's power of civil enforcement, both through certificate actions for certificated 
aviators, as well as via civil penalties applied through administrative law. These mechanisms serve to simultaneously apply punitive action to violators while also to act as a deterrent for future violators. These efforts are supported by recent regulation mandating registration for sUAS craft, to ensure ease of operator identification and subsequent accountability for unsafe UAS operations.

In addition to FAA regulatory efforts, a diverse range of Federal, state, and local criminal laws serve to hold operators accountable for UAS operations that inflict injury or damage, endanger public safety, or violate local laws or ordinances. Finally, the economic implications resulting from liability incurred through unsafe UAS operations serves as a further mechanism to hold operators accountable for unsafe UAS activities. While such legal tools may not initially deter the vast majority of UAS operators, widespread media coverage of such cases is likely to suppress or deter some unsafe UAS activities after the fact.

While legal and regulatory methods exist to hold operators accountable for unsafe UAS activities, they are currently applied relatively inconsistently, often based on the locale. Moreover, the FAA is currently taking a soft-handed, educational approach to prod operators to fly their UAS craft in accordance with Federal Aviation Regulations and safe practices. At this point, it is difficult to gauge the success of these efforts.

As the FAA continues its campaigns to educate UAS users in safe operational practices and restrictions, the stage is being set for the agency to shift policies to a more rigorous civil enforcement approach to managing UAS violations. The alarming increase in pilot reports of near mid-air collisions with UAS craft, coupled with widespread similar incidences of UAS devices causing property damage or injury, further incites the agency to pursue more aggressive enforcement action to curb degradation in NAS safety. It is likely that more aggressive enforcement action will follow swiftly on the heels of final implementation of sUAS rules under FAR Part 107. Moreover, sUAS violations will probably be designated by the agency for special emphasis enforcement, and be considered an aggravating factor until sUAS noncompliance becomes more controlled. In addition to more strict UAS enforcement policies for operational violations, it is likely that the FAA will also employ harsh enforcement action if UAS operators fail to register their platforms, as this behavior would be interpreted by the agency as being an intentional violation or willful attempt by the operator to evade detection and subsequent operational responsibility.

Novice UAS operators should make judicious use of safe practice resources, such as the B4UFLY app and other similar educational products offered by the 
FAA, AMA, AUVSI and other industry organizations to ensure compliance with Federal Aviation Regulations and accepted operational safe practices. Moreover, UAS operators should be proactive in reporting even suspected deviations or errors via the ASRS system, as self-reporting safety incidences are interpreted by the FAA as exhibiting a constructive attitude towards safety. For certificate holders and uncertificated UAS operators alike, use of the ASRS system will likely avert FAA enforcement action for inadvertent UAS safety violations.

Finally, it is vital for operators to become familiar with relevant local laws that apply to UAS operations. UAS operations that may be permissible in some areas, may be in violation of various state or local statutes or ordinances in other regions. Even if the respective UAS operation is permissible in accordance with FARs and local laws, the operator is not absolved from the potential liability associated with injuries or damage caused by the UAS craft. It is important for operators to understand the coverages, limitations, and exclusions of applicable insurance policies including homeowner coverage or UAS-specific insurance, such as policies furnished by the AMA. A failure to abide by the provisions of these policies could subject UAS operators to significant liability exposure with harsh financial repercussions. 


\section{References}

Abrams, A. (2015). Are drone accidents covered by insurance: As drone Christmas gifts rise, insurers and regulators warn of dangers. IB Times. Retrieved from http://www.ibtimes.com/are-drone-accidents-coveredinsurance-drone-christmas-gifts-rise-insurers-regulators-2240017

Academy of Model Aeronautics. (2014). 2015 insurance summary: The facts about AMA's insurance benefits for individual members. Retrieved from http://www.modelaircraft.org/files/InsuranceSummaryMembers.pdf

Ahlers, M. M. (2014). Pilot wins case against FAA over commercial drone flight. CNN. Retrieved from http://www.cnn.com/2014/03/06/us/drone-pilotcase-faa/index.html

Association for Unmanned Vehicle Systems International [AUVSI] \& Academy of Model Aeronautics [AMA]. (2015). Know before you fly. Retrieved from http://knowbeforeyoufly.org/

Aviation Safety Reporting System (2015). Unmanned Aerial Vehicle (UAV) Reports [Data File]. Retrieved from http://asrs.arc.nasa.gov/docs/rpsts/ uav.pdf

Bachman, J. (2015). Drone home videos no longer provoke FAA wrath. Bloomberg. Retrieved from http://www.bloomberg.com/news/articles/ 2015-04-14/drone-home-videos-on-youtube-no-longer-provoke-faa-wrath

Carey, B. (2014). Judge rules against FAA in landmark UAV challenge. AINonline. Retrieved from http://www.ainonline.com/aviation-news/201403-07/judge-rules-against-faa-landmark-uav-challenge

D.A.: Operators will be prosecuted for murder if 'intentional act of a drone' were to cause death. (2015). CBS Los Angeles. Retrieved from http://losangeles.cbslocal.com/2015/07/29/d-a-operators-will-beprosecuted-for-murder-if-intentional-act-of-a-drone-were-to-cause-death/

Drone flying over Seattle parade crashes, strikes woman. (2015). King 5 News. Retrieved from http://www.king5.com/story/news/local/seattle/2015/ 06/29/drone-knocks-woman-unconscious/29487191/ 
FAA to test method of locating illegal drone operators. (2015). Portland Press Herald. Retrieved from http://www.pressherald.com/2015/10/07/faa-totest-method-of-locating-illegal-drone-operators/

FAA Unmanned Aircraft Operations in the National Airspace Rule, 14 C.F.R. Part 91 (2007).

Federal Aviation Administration (n.d.a) B4UFLY general questions \& answers. Retrieved from https://www.faa.gov/uas/b4ufly/media/ UAS_B4UFLY_QandA.pdf

Federal Aviation Administration. (n.d.b). Law enforcement guidance for suspected unauthorized UAS operations. Retrieved from http://www.faa.gov/uas/regulations_policies/media/FAA_UASPO_LEA_Guidance.pdf

Federal Aviation Administration. (n.d.c) UAS enforcement $Q \& A$. Retrieved from http://www.faa.gov/uas/law_enforcement/media/UAS-EnforcementFAQs.pdf

Federal Aviation Administration. (2011). Aviation safety reporting program [AC00-46E]. Retrieved from http://asrs.arc.nasa.gov/docs/AC\%2000-46E.pdf

Federal Aviation Administration (2015a). FAA compliance and enforcement program (Incorporated with changes 1-10)[FAA Order No. 2150.3B]. Retrieved from http://www.faa.gov/documentLibrary/media/Order/ FAA_Order_2150_3B_W-Chg_10.pdf

Federal Aviation Administration. (2015b). Federal Aviation Administration compliance philosophy [FAA Order No. 8000.373]. Retrieved from http://www.faa.gov/documentlibrary/media/order/faa_order_8000.373.pdf

Federal Aviation Administration. (2015c). Model aircraft operations. Retrieved from https://www.faa.gov/uas/model_aircraft/

Federal Aviation Administration (2015d). No drone zone. Retrieved from https://www.faa.gov/uas/no_drone_zone/

Federal Aviation Administration. (2015e). Pilot, air traffic, and citizen reports of possible encounters with unmanned aircraft [Data file]. Retrieved from http://www.faa.gov/uas/media/UASEventsNov2014-Aug2015.xls 
Federal Aviation Administration. (2016a). B4UFLY smartphone app. Retrieved from https://www.faa.gov/uas/b4ufly/

Federal Aviation Administration. (2016b). UAS registration questions \& answers. Retrieved from https://www.faa.gov/registration/faqs

Gettinger, D. \& Michel, A.H. (2015). Drone sightings and close encounters: An analysis. Bard College Center for the Study of the Drone. Retrieved from http://dronecenter.bard.edu/files/2015/12/12-11-Drone-Sightings-andClose-Encounters.pdf

Goff, L. (2015). Drone pilot charged in U.S. Open crash. Queens Gazette. Retrieved from http://www.qgazette.com/news/2015-09-23/Front_Page/ Drone_Pilot_Charged_In_US_Open_Crash.html

Grady, M. (2015). Drone operator fined \$1.9 million. AVweb. Retrieved from http://www.avweb.com/avwebflash/news/Drone-Operator-Fined-19-Million224962-1.html

Hamilton, M. \& Rocha, V. (2015). \$75,000 in rewards offered to catch operators who flew drones above fires. Los Angeles Times. Retrieved from http://www.latimes.com/local/lanow/la-me-ln-reward-drone-arrests-20150728story.html

Harrison, J. (2014). UAV069 NTSB on FAA v. Pirker: Remanded. The UAV Digest. Retrieved from http://theuavdigest.com/tag/raphael-pirker/

Huerta v. Pirker, National Transportation Safety Board, CP-217, (Administrative Law Court 2014).

Kauh, E. (2015). FAA starts "no drone zone" campaign for Washington. AVWeb. Retrieved from http://www.avweb.com/avwebflash/news/FAA-Starts-NoDrone-Zone-Campaign-For-Washington-224091-1.html

Kesselman, S. (2014). Pirker decision overturned: FAA can fine for reckless UAS operation. Robotics Tomorrow. Retrieved from http://www.auvsi.org/ browse/blogs/blogviewer?BlogKey=e8ed680a-6e3d-474d-88b19eb5036d9b9a\&tab=recentcommunityblogsdashboard 
McKay, M. (2016). University of Kentucky student speaks out about crashing drone in football stadium. Lexington Herald Leader. Retrieved from http://www.kentucky.com/news/local/counties/fayette-county/ article53915475.html

Miletich, S. (2015). Drone operator charged with knocking out woman at Pride Parade. The Seattle Times. Retrieved from http://www.seattletimes.com/ seattle-news/crime/drone-operator-charged-with-knocking-out-woman-atpride-parade/

Morris, R. \& Thurston, G. (2015). Interim final rule regulatory evaluation: Regulatory and marking requirements for small unmanned aircraft (FAA Publication No. RIN 2120-AK82). Retrieved from https:/www.faa.gov/ news/updates/media/2015-12-13_2120-AK82_RIA.pdf

Registration and Marking Requirements for Small Unmanned Aircraft (Interim Final Rule), 80 FR 78593-78648. Retrieved from https://www.federalregister.gov/articles/2015/12/16/201531750/registration-and-marking-requirements-for-small-unmannedaircraft

Schrimpf, T. \& Russ, K. (2015). Recreational drones: Do homeowners' insurance policies provide coverage. Claims Journal. Retrieved from http://www.claimsjournal.com/news/national/2015/08/04/264918.htm

Serna, J. (2015). Drone pilots could get jail time, fine for violating new L.A. ordinance. Los Angeles Times. Retrieved from http://www.latimes.com/ local/lanow/la-me-ln-la-passes-new-drone-ordinance-20151014-story.html

Steinberg, J. \& Nelson, J. (2015). Drone over massive lake fire 'could've killed everybody in the air,' official says. San Bernardino Sun. Retrieved from http://www.sbsun.com/general-news/20150625/drone-over-massive-lakefire-couldve-killed-everybody-in-the-air-official-says

Tse, C. (2015). Drone operators could face jail time violating new city law. Laist. Retrieved from http://laist.com/2015/10/14/drone_law_la.php

U.S. House of Representatives Transportation \& Infrastructure Subcommittee. (2015). Ensuring safety in the era of Unmanned Aircraft Systems. Retrieved from http://transportation.house.gov/calendar/ eventsingle.aspx?EventID=399335 
Ungureanu, H. (2015). Police looking for the genius who crashed a DJI Phantom 3 drone into Seattle's ferris wheel. Tech Times. Retrieved from http://www.techtimes.com/articles/105933/20151112/police-looking-for-thegenius-who-crashed-a-dji-phantom-3-drone-into-seattles-ferris-wheel.htm 